\title{
PERCEIVED INSIDER STATUS AND JOB DESIGN PREDICT JOB ATTITUDES AND WORK PERFORMANCE OF RESTAURANT EMPLOYEES
}

\begin{abstract}
In this paper the role of perceived insider status (PIS) as a predictor of attitudinal and behavioral work outcomes and the role of core job characteristics as moderators of this relationship has been investigated. Data from 203 employees of a casual restaurant chain in Singapore provide support for the central hypotheses. The results suggest that objective employment characteristics (full-time vs. part-time and permanent vs. seasonal) predict PIS even when controlling for organizational tenure. Moreover, PIS predicts job satisfaction, turnover intention, in-role job performance as well as voice behavior and personal initiative. In addition to having significant main effects, enriched core job characteristics also moderate most of the relationships between PIS and the various outcomes. The article concludes with a discussion of some important implications of these findings for research and for managerial practice in the hospitality industry.
\end{abstract}

Key Words: In-role performance, Job design, Job satisfaction, Perceived insider status, Turnover intention, Voice behavior 
The hospitality industry workforce has traditionally been characterized by a substantial proportion of peripheral employees. These part-time, casual, seasonal, or short-contract employees provide a degree of flexibility to the employing organization that could not be achieved by relying solely on the services of a more permanent “core” workforce (Guerrier \& Lockwood, 1989). However, employing a two-tiered workforce also entails a number of potential disadvantages. For instance, an increased reliance on part-time workers can have unintended side effects by inhibiting the display of discretionary work behaviors that are critical for the success of service organizations (Stamper \& Van Dyne, 2001). Research suggests that this may be due to the fact that peripheral employees find it more difficult than their colleagues in the core workforce to perceive themselves as insiders of the organization (Stamper \& Masterson, 2002).

Research on the consequences of perceived insider status (PIS) is still in its early stages and some important questions have not been conclusively answered. For instance, empirical results regarding the relationship between measures of objective inclusion and the more subjective perception of insider status have not been conclusive (Stamper \& Masterson, 2002). Moreover, while there is evidence for a positive relationship between perceived insider status and work performance in the hospitality industry (Wang \& Kim, 2013), the relationship with other outcome variables that are relevant for the hospitality industry, such as challenging extra-role behaviors, has yet to be investigated. Last but not least, no research has looked at the role of potential moderators which could serve to buffer the negative effects on work outcomes that may result when employees fail to develop perceptions of insider status or, conversely, that may strengthen the positive effects that occur when PIS is achieved.

This study proposes to address several of these research gaps. First, the impact of fulltime vs. part-time and permanent vs. seasonal employment status on PIS as reported by a sample of employees from a casual restaurant chain in Singapore has been investigated. 
Second, the consequences of PIS for a broad range of attitudinal and behavioral work outcomes, including job satisfaction, turnover intention as well as in-role performance and two types of discretionary work behaviors have been assessed. Finally, the role of core job characteristics as moderators of the relationship between PIS and these outcomes has been included in the analysis. Results suggest that objective employment characteristics predict PIS and that PIS, in turn, is a predictor of important job attitudes and behaviors. They also suggest that core job characteristics play a moderating role such that the effect of PIS on job satisfaction, turnover intention and in-role performance is stronger for jobs low in core job characteristics, whereas for voice behavior and personal initiative it is stronger for enriched jobs.

\section{THEORY AND HYPOTHESES}

\section{Employment Status and Perceived Insider Status}

Differentiation in the employment status of various groups of employees is likely to be particularly salient in the hospitality industry. Not only does this industry rely heavily on parttime and/or seasonal employees (Nollen \& Axel, 1995) but it also has a long-standing tradition of differentiating between members of the core workforce and those employees that are considered to be more peripheral (Guerrier \& Lockwood, 1989). In this context, it is to be expected that employees develop different perceptions with regard to the extent to which they belong to their employing organizations, in other words: whether they perceive themselves to be insiders or outsiders.

Research suggested that PIS, which is defined as "the extent to which an individual employee perceives him or herself as an insider within a particular organization” (Stamper \& Masterson, 2002: 876), will have consequences for job attitudes and behaviors at work and that PIS is predicted by indicators of actual inclusion in an organization (Stamper \& Masterson, 2002). In their study, Stamper and Masterson (2002) used number of hours 
worked per week and organizational tenure as a proxy for actual inclusion. They suggested that employees who work longer for an organization have greater chances of familiarizing themselves with organizational procedures and norms, of gaining access to information and developing networks of relationships with important members of the organization, all of which should contribute to higher perceived insider status. However, they failed to find empirical support for this notion.

In this paper it is suggested that the objective employment status of an individual employee, i.e. whether individuals are employed full-time (rather than part-time), and whether their employment is permanent (rather than merely seasonal) should be a better predictor of a focal employee's PIS. This argument is based on the notion that full-time and permanent employees generally receive more substantial inducements and rewards from their employer than their colleagues who are in part-time or seasonal employment situations (Hipple, 1998). These inducements include preferential treatment with regard to human resources practices, such as training, promotions, and compensation and benefits, as well as greater attention and trust from their supervisors. Human capital theory (Becker, 1964) suggests that greater investment in and increased attention to a particular group of employees sends a strong signal that they belong to the core workforce and benefit from an insider status, while at the same time sending a corresponding signal to those on the periphery of the workforce that they are considered as outsiders. To the extent that different employees are clearly associated with one or the other group, this signaling effect should be expected to take hold rather quickly, to remain relatively stable over time, and to outweigh the mere influence of time spent in the organization. Based on this theoretical rationale the following hypothesis is proposed:

Hypothesis 1: Full-time work status (vs. part-time work status) and permanent employment (vs. seasonal employment) are positively associated with perceived insider status even when organizational tenure is controlled for. 


\section{Effects of Perceived Insider Status on Work Attitudes and Behaviors}

When individuals perceive themselves as insiders in an organization they believe that their contributions to the organization are valued, that they are appreciated by the organization and their peers and that they are part of an organizational in-group, in short: that they belong. Consistent with sociological theory on the norm of reciprocity (Gouldner, 1960) employees who feel that they are valued by their employer, that they belong and that they receive appreciation and support from their colleagues should develop, in response, positive attitudes towards the organization, which will be reflected in greater job satisfaction and greater commitment to the organization (Allen \& Meyer, 1990). This theoretical argument has found empirical support in several studies. For instance, Van Dyne and Ang (1998) and Moorman and Harland (2002) reported that perceptions of higher relationship quality with their employing organization were positively related to employees’ level of organizational commitment. Stronger organizational commitment typically is associated with a lower intention to quit. Knapp, Smith, and Sprinkle (2014) found that perceived insider status was a significant predictor of job satisfaction and turnover intentions even when psychological ownership and organizational identification were controlled for. Based on this theoretical rationale it is suggested that perceived insider status should have a positive main effect on job satisfaction and a negative main effect on turnover intention. Formally stated:

Hypothesis 2: Perceived insider status is positively associated with job satisfaction and negatively associated with turnover intention.

In addition to the attitudinal consequences outlined above, perceived insider status should also be associated with important behavioral outcomes. Social exchange theory (Blau, 1964) suggests that in situations of unspecified social exchange, individual contributions will be based on the promise of reciprocation. For perceived insiders, the preferential inducements they receive from their employer will lead to employees feeling obliged to reciprocate by 
showing increased effort at work. As a result, PIS should be positively associated with restaurant employees' in-role job performance. This argument is supported by empirical findings suggesting that PIS is positively related to task performance (Wang \& Kim, 2013).

Moreover, since permanent and full-time employment signals greater commitment to the employment relationship than seasonal and part-time employment, these employment conditions are also more likely to lead to the development of relational trust (Rousseau, Sitkin, Burt, \& Camerer, 1998). Trust theory suggests that when relational trust has been built with the organization, employees are more willing to go beyond the call of duty and engage in discretionary, extra-role job performance (March \& Simon, 1958). Past research has found empirical support for this hypothesized relationship between PIS and extra-role job performance in the form of organizational citizenship behavior (Stamper \& Masterson, 2002; Hui, Lee, \& Wang, 2015).

This study focuses on two types of extra-role job performance that are particularly relevant for the hospitality industry and have been investigated in previous hospitalityindustry related studies: voice behavior (Raub \& Robert, 2013) and proactive behavior (Raub \& Liao, 2012) in the form of personal initiative. Voice behavior involves making constructive suggestions for improvements in work processes or procedures (Van Dyne \& LePine, 1998). Proactive behavior in the form of personal initiative has been described as a long-term oriented, proactive, change-oriented and persistent approach to work (Frese et al., 1997). Summarizing the theoretical rationales for a positive relationship between PIS and in-role performance as well as discretionary, extra-role performance, the following hypothesis is suggested:

Hypothesis 3: Perceived insider status is positively associated with in-role performance, voice behavior, and personal initiative. 


\section{Core Job Characteristics and Their Consequences for Work Attitudes and Behaviors}

Research on job design focuses on the importance of the task, knowledge, social and contextual characteristics of work on the attitudinal and behavioral responses of employees (Morgeson \& Humphrey, 2006). Hackman and Oldham $(1975,1976)$ identified five core job characteristics, including skill variety (the variety of different activities that need to be carried out in a job), task identity (the degree to which the job allows for the completion of a whole identifiable piece of work), task significance (the degree to which the job has a substantial impact on the lives or work of other people), autonomy (the extent to which the job provides for independence and discretion) and feedback (the extent to which the job or other people provide feedback on the effectiveness with which the job is carried out). The reliability and validity of the job characteristics model for hospitality industry employees has been demonstrated by Lee-Ross (1998a, 1998b).

Job characteristics theory suggests that these core job characteristics lead to desirable psychological states, including experienced meaningfulness of work, experienced responsibility for outcomes and knowledge of work activities. These psychological states, in turn, should lead to higher job satisfaction and lower absenteeism and turnover. In the context of the hospitality industry, empirical results obtained in several studies (Bart Bartlett, 2007; Kim and Jogaratnam, 2010; Ozturk, Hancer, \& Im, 2014) support this prediction. The fundamental predictions of job characteristics theory are expected to be replicated in this sample. Hence, the following hypothesis:

Hypothesis 4: Enriched work design (i.e. high levels of skill variety, task identity, task significance, autonomy and feedback) is positively associated with job satisfaction and negatively associated with turnover intention.

Moreover, Hackman \& Oldham suggested that these critical psychological states also predict higher work performance and intrinsic motivation. Again, a positive association with in-role work performance is expected to be replicated in this sample and, given the relevance 
of discretionary work behaviors for the hospitality industry outlined above, the scope of this study has been extended to investigate whether this relationship also holds for this type of extra-role work performance. Formally stated:

Hypothesis 5: Enriched work design (skill variety, task identity, task significance, autonomy, feedback and social support) is positively associated with in-role performance, voice behavior, and proactive behavior (personal initiative).

\section{Core Job Characteristics as Moderators of the PIS - Work Outcomes Relationship}

Existing research has not investigated whether the effect of PIS on attitudinal and behavioral work outcomes may be influenced by the social information that can be derived from elements of the work context such as job design. In other words: Does PIS have universally positive effects or does it interact with the way employees perceive their work environment. Social information processing theory (Salancik \& Pfeffer, 1978) suggests that the characteristics of a workplace are not given but socially constructed by members of the organization. Job or task characteristics, and the social information that is available about them, allows employees to construct perceptions of their work environment and of their own needs, attitudes and behaviors. In the case of job design, social information processing theory suggests that the way a job is designed provides important information to employees about how much the organization values their contributions, and to what extent it trusts them to be able and willing to complete complex tasks. Enriched job characteristics send the signal that the employee has greater responsibility for the successful completion of work and the success of the employing organization and, as a result, provide for a more meaningful experience of the work environment and of the work itself. Depending on the degree of PIS these signals may be interpreted differentially and the weight they carry for employees may also vary. This suggests the notion of a compensatory relationship between PIS and work design.

For employees who work in very poorly-designed jobs (i.e. with low levels of skill variety, task identity, task significance, autonomy, and feedback) the perception of 
organizational insider status may make a huge difference for job attitudes and behaviors. For employees in such jobs, perceiving themselves as an organizational insider may be equivalent to thinking “My job may be simple, but I count for something in the organization.” In other words, PIS would compensate for the limited motivating potential of the job.

Conversely, employees working in enriched jobs already perceive responsibility, control and meaning in their jobs. For them, the perception of insider or outsider status may make less of a difference. They may think "My job is stimulating, meaningful and involves responsibility; hence I am important for the organization, regardless of my official status.” As a result, moving from outsider to insider status should be associated with increased job satisfaction and job performance and decreased turnover intention for employees in poorlydesigned jobs, whereas this effect is supposed to be significantly weaker or even non-existent for enriched jobs. The hypothesized interaction between PIS and enriched work design could be formally stated as follows:

Hypothesis 6: Enriched work design (skill variety, task identity, task significance, autonomy, feedback and social support) moderates the relationship between PIS and attitudinal/behavioral work outcomes in such a way that the magnitude of the relationship is significantly stronger for individuals working in poorly-designed jobs than for those working in enriched jobs.

Figure 1 summarizes the hypothesized relationships.

Insert Figure 1 about here

\section{METHODOLOGY}

\section{Sampling and Procedure}

Data for this study were collected from entry-level F\&B employees in nine outlets of a casual restaurant chain in Singapore. The setting was selected because of the substantial proportion of seasonal and part-time workers that are employed by this chain. A workforce 
with a sufficient amount of variability in terms of employment conditions was essential for an empirical test of the hypotheses in this study.

Three different data sources were used with a view to minimizing the potential for common method bias. Data on work status (full-time vs. part-time), type of employment (permanent vs. seasonal employment) and tenure with the restaurant were retrieved from the chain's HR records with the help of the HR manager. In addition, two separate questionnaires were prepared. Employees received a questionnaire that included measures of job design, perceived insider status and attitudinal outcomes (job satisfaction and turnover intention). The supervisors of the participating employees were asked to complete a separate questionnaire with measures of behavioral outcomes (in-role performance, voice behavior and personal initiative). All questionnaires were pre-tested on a small sample of bachelor's students in a major hospitality school in Europe. The students came from geographic backgrounds and had mother tongues similar to those of the respondents in the main sample. Minor changes in questionnaire wording were made based on the feedback from this pilot group. In the actual sample, the employee and supervisor questionnaires were matched through an inconspicuous numerical code printed at the bottom of each questionnaire.

Since English proficiency is a condition for employment in this chain, all questionnaires were prepared in the English language. The questionnaires were distributed on the premises of each participating restaurant by a research assistant of the principal investigator. All respondents were allowed to fill out questionnaires during working hours and were ensured full confidentiality. Completed questionnaires were collected in a sealed box and collected by the research assistant between one and two weeks after distribution. In order to reinforce the confidentiality promise and to mitigate response bias, the management of the restaurant chain was not given access to the completed questionnaires and only summary statistics were reported to the top management team. 
From 312 employees a total of 32 were on leave on the day of data collection and 77 did not return questionnaires. The 203 usable questionnaires that were returned represent a response rate of 73\%. 18 direct supervisors of the surveyed employees filled out an average of 11 questionnaires. The response rate for supervisors was $98 \%$.

$36 \%$ of the respondents were female, their average age was 28.00 years (s.d. $=4.86$ years) and their average tenure was 1.01 years (s.d. $=.91$ years). $60 \%$ were employed full time, whereas $40 \%$ were part-timers. $25 \%$ were employed only on a seasonal basis, while 75\% were employed permanently.

\section{Measures}

Perceived insider status. Perceived insider status was measured with Stamper and Masterson’s (2002) six-item scale. (Sample items include “I feel very much a part of my work organization" and "My work organization makes me believe that I am included in it”) ( $\alpha=.84)$.

Core job characteristics. The five core job characteristics were assessed with items from Morgeson \& Humphrey’s (2006) Work Design Questionnaire (WDQ). The scores on the five dimensions were averaged to obtain a composite measure of core job characteristics ( $\alpha=.96)$. Skill variety was assessed with four items. (Sample items include "The job requires a variety of skills" and "The job requires me to utilize a variety of different skills in order to complete the work”). Task identity was measured with four items. (Sample items include "The job involves completing a piece of work that has an obvious beginning and end" and "The job is arranged so that I can do an entire piece of work from beginning to end”). Task significance was assessed with four items. (Sample items include "The results of my work are likely to significantly affect the lives of other people" and "The job itself is very significant and important in the broader scheme of things”). Autonomy was assessed with six items, including three items for work-methods autonomy and three items for decision-making autonomy. (Sample items include “The job gives me a chance to use my personal initiative or judgment 
in carrying out the work" and "The job allows me to make decisions about what methods I use to complete my work”). Feedback was measured with six items, including three items for feedback from job and three items for feedback from others. (Sample items include "The job itself provides feedback on my performance.” and “I receive a great deal of information from my manager and coworkers about my job performance”).

Job satisfaction. Job satisfaction was measured with the 4-item scale developed by Quinn \& Sheppard (1974). Sample items include “All in all, I am very satisfied with my current job” and "In general, my job measures up to the sort of job I wanted when I took it" $(\alpha=.84)$

Turnover intention. A 4-item scale developed by Kelloway, Gottlieb, \& Barham (1999) was used to measure turnover intention. Sample items include "I am thinking about leaving this organization" and "I am planning to look for a new job" $(\alpha=.90)$.

In-role performance. In-role performance was measured with Williams \& Anderson’s (1991) five positively-worded items. Sample items for in-role performance include “Adequately completes assigned duties” and “Fulfills responsibilities specified in job description" $(\alpha=.94)$.

Voice behavior. Voice behavior was measured with six items from Van Dyne and LePine (1998). Sample items for voice include "This particular co-worker speaks up in this department with ideas for new projects or changes in procedures” and “This particular coworker communicates his/her opinions about work issues to others in this department even when his/her opinion is different and others in the department disagree with him/her" $(\alpha=.93)$.

Personal initiative. The 7-item scale developed by Frese et al. (1997) was used to measure personal initiative. Sample items include “Actively attacks problems” and "Is particularly good at realizing ideas" $(\alpha=.89)$. 
Control variables included gender and age. All rating scales ranged from 1, "strongly disagree”, to 5, “strongly agree”.

\section{RESULTS}

Table 1 shows zero-order correlations among the study variables as well as their internal consistency reliabilities (Cronbach’s alphas). All internal consistency reliabilities were in a range from $.84-.96$, comfortably exceeding the conventional cutoff point of .70 .

Insert Table 1 about here

To assess the discriminant validity of our various constructs we conducted a series of three confirmatory factor analyses. Our hypothesized 7-factor model demonstrated excellent fit $(\chi 2=3950.28, \mathrm{RMSEA}=.089, \mathrm{NFI}=.94, \mathrm{CFI}=.97, \mathrm{IFI}=.97, \mathrm{SRMR}=.069)$. Moreover, this model fit the data significantly better than a competing two-factor model in which we regrouped employee-assessed and supervisor-assessed indicators on two separate factors $(\Delta \chi 2(1)=2334.65 ; \mathrm{p}<.001)$ and also significantly better than a one-factor model in which all indicators were allowed to load on a single factor $((\Delta \chi 2(21)=5059.53 ; \mathrm{p}<.001)$. An overview of the fit statistics for these confirmatory factor analyses is shown in Table 2.

Insert Table 2 about here

The 203 respondents are nested within 18 supervisors who in turn are nested within 9 establishments. Despite the fact that the theoretical model does not specify any predictors at the supervisor level (Level 2) or establishment level (Level 3) the assumption of nonindependence of employee-level observations may be violated due to the nested structure of the data. This implies that supervisor-level and establishment-level effects need to be controlled for (Bliese, 2000). Therefore, a random coefficient modeling (RCM) approach was chosen for all the analyses that included supervisor-assessed outcome variables. Supervisor- 
level and establishment-level effects were accounted for by including a random intercept term at both levels. All RCM analyses were carried out in version 2.15.1 of the R base module ( $\mathrm{R}$ Core Team, 2012) in combination with version 3.1 of the "nlme” multilevel package (Pinheiro et al., 2008).

The first analysis does not include any supervisor-assessed variables. Therefore, a multiple regression approach using SPSS version 22 was used. Table 3 shows the results for a regression of perceived insider status on work status and seasonal employment, with gender, age and tenure as controls. The result provides support for Hypothesis 1 in that both workstatus and employment type are positively associated with perceived insider status. The signs of the regression coefficients suggest that full-time employment (as opposed to part-time employment) and permanent employment (as opposed to seasonal employment) are positively associated with perceived insider status.

Insert Table 3 about here

A post-hoc analysis was conducted to compare mean levels of PIS across four groups, i.e. seasonal part-time employees (Group 1), seasonal full-time employees (Group 2), permanent part-time employees (Group 3) and permanent full-time employees (Group 4). Results of a single-factor ANOVA (cf. Table 4) demonstrate that there are significant differences between group means $(\mathrm{F}=27.00, \mathrm{p}<.001)$. Multiple comparisons with Scheffe's F further demonstrate that permanent full-time employees display the highest mean level of PIS, which is significantly greater $(\mathrm{p}<.01)$ than those of all other groups (cf. Table 5). Permanent part-time employees have the second highest mean level of PIS, marginally significantly greater $(\mathrm{p}<.10)$ than that of seasonal full-time and significantly greater $(\mathrm{p}<.01)$ than that of seasonal part-time employees. The two groups of seasonal employees show the lowest levels of PIS, with the difference between the two groups not being statistically 
significant. These results are aligned with the results from the multiple regression analysis and suggest that permanent vs. seasonal employment has the most substantial impact on the perception of insider status, with full-time vs. part-time work status accounting for a somewhat smaller proportion of the variance in PIS.

Insert Tables 4 and 5 about here

Tables 6 and 7 summarize results for the main and interactive effects of PIS and core job characteristics on the five outcome variables. For each dependent variable the results are indicated in separate columns for main effects only and for a model with interaction term. PIS has a significant positive main effect on job satisfaction $(\beta=.22$, $\mathrm{p}<.01)$, in-role performance $(\gamma=.18, \mathrm{p}<.01)$, voice behavior $(\gamma=.15, \mathrm{p}<.01)$ and personal initiative $(\gamma=.14, \mathrm{p}<.05)$ and a significant negative main effect on turnover intention $(\beta=-.26, p<.01)$. The composite measure of core job characteristics has a significant positive main effect on job satisfaction ( $\beta$ $=.52, \mathrm{p}<.01)$, in-role performance $(\gamma=.47, \mathrm{p}<.01)$, voice behavior $(\gamma=.44, \mathrm{p}<.01)$ and personal initiative $(\gamma=.48, \mathrm{p}<.01)$ and a significant negative main effect on turnover intention $(\beta=-.54, \mathrm{p}<.01)$. These results confirm the main effects proposed in Hypothesis 2 Hypothesis 5.

Insert Tables 6 and 7 about here

The second column for each dependent variable in Tables 5 and 6 indicates results for a model with an interaction term for core job characteristics $x$ PIS. While the interaction is not significant for job satisfaction $(\beta=-.06, \mathrm{p}>.05)$, results suggest significant interactions for turnover intention $(\beta=.15, \mathrm{p}<.01)$, in-role performance $(\gamma=-.13, \mathrm{p}<.01)$, voice behavior $(\gamma$ $=.11, \mathrm{p}<.05)$ and personal initiative $(\gamma=.10, \mathrm{p}<.05)$. These results provide partial support for the interaction proposed in Hypothesis 6. 
To facilitate the interpretation of the interaction results, simple slopes were plotted for every interaction at one standard deviation above and one standard deviation below the mean for the predictor variable, following the procedures recommended by Aiken \& West (1991). Figure 2 demonstrates that for individuals in poorly-designed jobs, an increase in perceived insider status is associated with a significant decrease in turnover intentions. Conversely, for individuals in enriched jobs, the slope of the relationship is close to zero. A similar pattern emerges in Figure 3. For individuals in poorly-designed jobs, an increase in perceived insider status is associated with a significant increase in in-role performance, whereas for individuals in enriched jobs, the slope of the relationship is close to zero. These results provide full support for the hypothesized interaction. They suggest that for poorly-designed jobs, the perception of insider status has significant beneficial effects (i.e. reduced turnover intentions and increased in-role performance) whereas for enriched jobs the perception of insider status does not matter.

Insert Figures 4 and 5 about here

Figures 4 and 5 illustrate the interaction results for the outcome variables of voice behavior and personal initiative. The interaction plots indicate that the form of the interaction does not correspond to the hypothesized pattern. Both plots show that for individuals in poorly-designed jobs, the perception of insider status is not significantly related to voice behavior and personal initiative. Conversely, for employees in enriched jobs, perceptions of insider status are associated with increased voice behavior and increased personal initiative. While the results support the hypothesis of an interaction between job design and PIS, the pattern of the interaction suggests a synergistic rather than a compensatory relationship. 


\section{DISCUSSION}

This study makes a number of contributions to research and managerial practice in the hospitality industry. First, the results suggest that measures of objective inclusion, such as full-time work-status and permanent employment are strong predictors of PIS in hospitality firms. Second, the study demonstrates that PIS has beneficial effects on a broad range of important attitudinal and behavioral outcomes in the job context of a hospitality firm. Most notably, the study enhances our understanding of the role PIS plays for challenging discretionary work behaviors. Last but not least, the results provide an interesting contextual refinement by demonstrating that job characteristics represent important boundary conditions for the relationship between PIS and various outcomes.

\section{Implications for Research}

Previous research has been inconclusive with regard to the relationship between actual inclusion and perceived insider status. For instance, Stamper and Masterson (2002) argued that actual inclusion, such as the difference between being a part-time vs. a full-time employee, should be positively related to PIS. However, their empirical results did not support this hypothesis. The null result may be attributed to their operationalization of actual inclusion in the form of tenure and average hours worked per week. This study is the first empirical investigation that operationalizes actual inclusion squarely as belonging to different employment groups (i.e. permanent vs. seasonal and full-time vs. part-time employees). The results clearly suggest that there are significant differences in perceived insider status between four groups of employees and support the notion that both employment status (permanent vs. seasonal) and work status (part-time vs. full-time) are associated with PIS. These findings constitute an important contribution to the debate about the relationship between actual inclusion and PIS. 
Secondly, the study adds to the relatively sparse research on a perceptual variable that is particularly relevant for the hospitality industry: perceived insider status (PIS). There is preliminary evidence in past research which indicates that PIS is positively related to job satisfaction (Chen \& Aryee, 2007; Knapp et al., 2014) and organizational commitment (Chen \& Aryee, 2007; Lapalme et al., 2009) and negatively related to turnover intentions (Armstrong-Stassen \& Schlosser, 2011; Knapp et al., 2014). With regard to behavioral outcomes, research has suggested a positive relationship with task performance (Chen \& Aryee, 2007; Wang \& Kim, 2013). This study replicates the results of these studies in the context of the hospitality industry. More importantly, it provides a significant extension with regard to the impact of PIS on discretionary work behaviors.

There are only two prior studies that have investigated this relationship. Lapalme et al. (2009) found a positive relationship with interpersonal facilitation behavior and Stamper and Masterson (2002) suggested a positive association with altruism. Both interpersonal facilitation and altruism are clearly affiliative types of discretionary work behavior (Van Dyne, Cummings, \& McLean Parks, 1995). This study offers the first investigation of the impact of PIS on voice behavior and personal initiative, two types of challenging discretionary behavior that are of great importance for service contexts in general and in particular for the hospitality industry. Front-line service employees are in direct contact with the organization's clients and are uniquely positioned to voice constructive suggestions for improvements in service delivery processes which can lead to greater customer satisfaction (Raub \& Robert, 2013; Stamper \& Van Dyne, 2001). Moreover, when service employees take personal initiative to anticipate guest problems and address service delivery issues at the root, the resulting proactive customer service performance has been shown to translate into greater guest satisfaction (Raub \& Liao, 2012). The results of this study suggest that PIS is a significant predictor of these important types of discretionary behaviors. 
Finally, the study also provides an important theoretical contribution with regard to the boundary conditions of the relationship between PIS and important attitudinal and behavioral outcomes. The results suggest that PIS not only has a significant direct effect on the outcome variables investigated in this study but that this effect is moderated by job design. For the relationship between PIS and turnover intention and that between PIS and in-role performance, the pattern of the interaction corresponds to what was hypothesized. Enriched job design, i.e. jobs that are characterized by greater average levels of skill variety, task identity, task significance, autonomy and feedback, seem to compensate for perceived insider status in predicting job satisfaction and turnover intention. For employees in enriched jobs, PIS does not make a significant difference for their attitudes towards the job and the organization. However, for employees who need to deal with the hardship of poorly-designed jobs, which provide little potential for intrinsic motivation and satisfaction, the perception of belonging to the organization compensates for the shortcomings of the job and provides for a significant boost in job satisfaction and a corresponding reduction in turnover intention.

The results for voice behavior and personal initiative were surprising in that they suggest a synergistic interaction rather than the compensatory interaction that was hypothesized. In other words, PIS had a stronger positive effect on voice behavior and personal initiative for employees in jobs with an enriched design. The reason for this result may have to do with the unique nature of these forms of discretionary behavior. As opposed to interpersonal and cooperative types of discretionary behavior, such as helping or interpersonal facilitation, voice behavior and personal initiative are characterized by a challenging nature. They are change-oriented and may be interpreted as questioning the status quo in the organization (Van Dyne et al., 1995). Poorly-designed jobs provide little experience of meaningfulness, little information about the results of job activities, and little perceived responsibility for work outcomes. As a result, employees in such jobs - even when 
they perceive insider status - may lack insight into the nature of the service delivery processes of which they are a part, as well as the motivation to suggest any meaningful changes. However, employees in enriched jobs that are characterized by greater experienced meaningfulness, more knowledge about work results and greater experienced responsibility may have both the necessary contextual knowledge and the required motivation to engage in challenging behaviors. As a result, perceived insider status may translate into significantly greater engagement in voice behavior and personal initiative for these employees for this group of employees.

\section{Limitations}

Like every study this research has certain limitations. Some of these limitations are related to research design and methods. Most fundamentally, due to the cross-sectional design of this study, causal inferences are not warranted. In addition, a large number of measures in this study were assessed via self-reports. However, the fact that behavioral outcome variables were assessed by supervisors attenuates concerns about the possible impact of common method variance (Podsakoff et al., 2003) and is a distinct methodological strength of this study.

With regard to the theoretical model, some additional limitations deserve to be noted. This study focuses on only five core job characteristics. The literature on work design suggests a broad range of additional job characteristics that might have been included in this study and could have enriched the results. Moreover, there is a range of contextual variables pertaining to organizational culture, organizational climate and leadership that may serve as predictors of PIS or as additional moderators of the relationship between PIS and the focal outcomes of this study, which may have merited inclusion. Last but not least, even though a cross-cultural perspective was beyond the scope of this study, the characteristics of the sample 
and the fact that data were collected in the particular economic and cultural context of the restaurant industry in Singapore may limit the generalizability of the results.

\section{Implications for Practice and Recommendations}

The results of this study have a number of relevant implications for managerial practice in the hospitality industry. First of all, they highlight the importance of a better understanding of the extent to which perceived insiders and perceived outsiders differ in their attitudes towards their job and their organization as well as in their work behaviors. As a first step towards putting the results of this study into practice, managers should analyze their organizations with regard to the presence of part-time and seasonal employees. Results clearly suggest that type of employment and work status are associated with PIS. Therefore, the higher the proportion of seasonal and part-time employees in the total workforce, the greater the likelihood that there will be significant differences in PIS.

If managers want to reap the attitudinal and behavioral benefits associated with PIS they can influence perceptions of insider status by offering more permanent forms of employment. While the results of this study point towards the importance of objective inclusion as one way of increasing PIS, many alternative means of promoting PIS deserve to be explored. Organizations often employ different sets of HR policies for members of the core vs. the peripheral workforce (Guerrier \& Lockwood, 1989). Harmonization of employment conditions and standardization of HR policies can send a signal to more peripheral employees that the organization values their services as much as those provided by the core of the workforce. In a similar vein, good relationships at work and positive leadership practices can go a long way in creating a perception of belonging. Managers should strive to create a supportive organizational culture and should engage in empowering leadership practices (Arnold et al., 2000; Raub \& Robert, 2013), thereby sending a clear signal to all employees that they belong to the team. The implementation of any or a combination of the above 
managerial practices is likely to contribute to a situation where even part-time and seasonal employees may develop stronger perceptions of being organizational insiders.

The results also highlight that PIS has an impact on a broad range of important outcomes. It is associated with greater job satisfaction and lower turnover intention. In addition, it is also positively related to both in-role performance and specific forms of discretionary work performance. These results suggest that when organizations choose to provide employment conditions that are conducive to PIS, they may benefit in multiple ways. Lower turnover intentions should lead to reduced labor turnover and the associated financial benefits that are associated with it (Hinkin \& Tracey, 2000). Greater job satisfaction may spill over into greater customer satisfaction, particularly for employees in front-line service roles, and greater engagement in voice and proactive work behaviors may ensure that problems in the service delivery process are quickly uncovered and are fixed at the root (Rank, Carsten, Unger, \& Spector, 2007).

Last but not least, the results of this study suggest that managers of hospitality organizations can target employment status changes at specific groups of employees depending on the outcomes that are most desirable. If the focus is on reducing turnover and improving in-role job performance, the payoff for more permanent employment and the resulting increase in PIS will be greatest for jobs that are characterized by poor job design. For employees in these jobs, more permanent employment will signal a greater commitment from the organization, which should lead to a pay back in the form of greater commitment to their employer and better performance. For managers who are operating in a tight labor market, where satisfaction and turnover rates are important considerations, this is a significant conclusion. However, if the focus is on soliciting more suggestions for improvements in service delivery and/or a more proactive stance towards service delivery, increased PIS will lead to the best results for employees who work in enriched jobs. 


\section{Suggestions for future research}

Beyond the findings of this study there are a number of additional research questions that would be worthy of further exploration. First of all, the current study investigates a limited range of core job characteristics. In addition to these task-focused features, the work design literature also distinguishes a range of knowledge characteristics, social characteristics and work context characteristics (Morgeson \& Humphrey, 2006) that are likely to have an impact not only on PIS but also on the focal outcomes of this study. An inclusion of these characteristics would allow for a more comprehensive understanding of how job characteristics influence these outcomes and how they interact with PIS. Secondly, as mentioned earlier, there are numerous contextual variables that are likely to influence both perceptions of insider status as well as attitudinal and behavioral outcomes investigated in this study. They include, but are not limited to organizational culture and climate (Schneider, 1990), perceived organizational support (Eisenberger et al., 1986) and empowering leadership practices (Arnold et al., 2000; Raub \& Robert, 2013). These variables would provide for numerous opportunities to extend the current theoretical framework and test main effects as well as mediation and moderated mediation models. Finally, there are numerous cultural values at the national level as well as at the individual level (Schwartz, 1992) that are likely to have an impact on how strongly both objective employment characteristics as well as contextual factors influence PIS. In particular, the moderating effect of values related to power distance and collectivism at the national level (Hofstede, 1980) as well as individual values related to power, achievement and conformity (Schwartz, 1990) could be interesting to explore in this context. The results of this study will hopefully stimulate fresh thinking and additional research on the role of perceived insider status in hospitality organizations and the promises (and limits) of promoting desirable attitudinal and behavioral employee reactions through conscious choices in the realm of employment status and job design. 


\section{REFERENCES}

Aiken, L. S., \& West, S. G. (1991). Multiple regression: Testing and interpreting interactions. Newbury Park, CA: SAGE.

Armstrong-Stassen, M., \& Schlosser, F. (2011). Perceived organizational membership and the retention of older workers. Journal of Organizational Behavior, 32, 319-344.

Arnold, J. A., Arad, S., Rhoades, J. A., \& Drasgow, F. (2000). The empowering leadership questionnaire: The construction and validation of a new scale for measuring leader behaviors. Journal of Organizational Behavior, 21, 249-269.

Bart Bartlett, A. L. (2007). Job characteristics and job design in table-service restaurants. Journal of Human Resources in Hospitality \& Tourism, 6, 23-36.

Becker, G. S. (1964). Human capital. New York: Columbia University Press.

Blau, P. (1964). Exchange and power in social life. New York: John Wiley and Sons.

Bliese, P. D. (2000). Within-group agreement, non-independence, and reliability: Implications for data aggregation and analysis. In K. J. Klein \& S. W. J. Kozlowski (Eds.), Multilevel theory, research, and methods in organizations: Foundations, extensions, and new directions (pp. 349-381). San Francisco: Jossey-Bass.

Chen, Z. X., \& Aryee, S. (2007). Delegation and employee work outcomes: An examination of the cultural context of mediating processes in China. Academy of Management Journal, 50(1), 226-238.

Eisenberger, R., Huntington, R., Hutchison, S., \& Sowa, D. (1986). Perceived organizational support. Journal of Applied Psychology, 71, 500-507.

Frese, M., Fay, D., Hilburger, T., Leng, K., \& Tag, A. (1997). The concept of personal initiative: Operationalization, reliability and validity in two German samples. Journal of Occupational \& Organizational Psychology, 70, 139-161. 
Gouldner, A. W. (1960). The norm of reciprocity: A preliminary statement. American Sociological Review, 25, 161-178.

Guerrier, Y., \& Lockwood, A. (1989). Core and peripheral employees in hotel operations. Personnel Review, 18, 9-15.

Hackman, J. R., \& Oldham, G. R. (1975). Development of the Job Diagnostic Survey. Journal of Applied Psychology, 60, 159-170.

Hackman, J. R., \& Oldham, G. R. (1976). Motivation through the design of work: test of a theory. Organizational Behavior and Human Performance, 16, 250-279.

Hinkin, T. R., \& Tracey, J. B. (2000). The cost of turnover: Putting a price on the learning curve. Cornell Hotel and Restaurant Administration Quarterly, 41(3), 14-21.

Hipple, S. (1998). Contingent work: Results from the second survey. Monthly Labor Review, 121, 22-35.

Hofstede, G. (1980). Culture's consequences: International differences in work-related values. Beverly Hills: SAGE.

Hui, C., Lee, C., \& Wang, H. (2015). Organizational inducements and employee citizenship behavior: The mediating role of perceived insider status and the moderating role of collectivism. Human Resource Management, 54, 439-456.

Kelloway, E. K., Gottlieb, B. H., \& Barham, L. (1999). The source, nature, and direction of work and family conflict: A longitudinal investigation. Journal of Occupational Health Psychology, 4, 337-346.

Kim, K., \& Jogaratnam, G. (2010). Effects of individual and organizational factors on job satisfaction and intent to stay in the hotel and restaurant industry. Journal of Human Resources in Hospitality \& Tourism, 9, 318-339.

Knapp, J. R., Smith, B. R., \& Sprinkle, T. A. (2014). Clarifying the relational ties of organizational belonging: Understanding the roles of perceived insider status, 
psychological ownership, and organizational identification. Journal of Leadership \& Organizational Studies, 21(3), 273-285.

Lapalme, M., Stamper, C. L., Simard, G., \& Tremblay, M. (2009). Bringing the outside in: Can “external” workers experience insider status? Journal of Organizational Behavior, 30(7), 919-940.

Lee-Ross, D. (1998). A practical theory of motivation applied to hotels. International Journal of Contemporary Hospitality Management, 10, 68.

Lee-Ross, D. (1998). The reliability and rationale of Hackman and Oldham's Job Diagnostic Survey and Job Characteristics Model among seasonal hotel workers. International Journal of Hospitality Management, 17, 391.

March, J. G., \& Simon, H.A. (1958). Organizations. Cambridge: Blackwell Publishers.

Moorman, R. H., \& Harland, L. K. (2002). Temporary employees as good citizens: Factors influencing their OCB performance. Journal of Business and Psychology, 17, 171-187.

Morgeson, F. P., \& Humphrey, S. E. (2006). The work design questionnaire: Developing and validating a comprehensive measure for assessing job design and the nature of work. Journal of Applied Psychology, 91, 1321-1339.

Nollen, S. D., \& Axel, H. (1995). Managing contingent workers: How to reap the benefits and reduce the risks. New York: AMACOM.

Ozturk, A. B., Hancer, M., \& Im, J. Y. (2014). Job characteristics, job satisfaction, and organizational commitment for hotel workers in Turkey. Journal of Hospitality Marketing \& Management, 23, 294-313.

Pinheiro, J., Bates, D., DebRoy, S., Sarkar, D. and the R Development Core Team (2012). nlme: Linear and Nonlinear Mixed Effects Models. R package version 3.1-104. 
Podsakoff, P. M., MacKenzie, S. B., Lee, J. Y., \& Podsakoff, N. P. (2003). Common method biases in behavioral research: A critical review of the literature and recommended recipes. Journal of Applied Psychology, 8, 879-903.

Quinn, R. P., \& Shepard, L. G. (1974). The 1972-1973 quality of employment survey. Ann Arbor: Institute for Social Research, University of Michigan.

R Core Team (2012). R: A language and environment for statistical computing. R Foundation for Statistical Computing, Vienna, Austria. ISBN 3-900051-07-0, URL http://www.Rproject.org/

Rank, J., Carsten, J. M., Unger, J. M., \& Spector, P. E. (2007). Proactive customer service performance: Relationships with individual, task, and leadership variables. Human Performance, 20, 363-390.

Raub, S. P., \& Robert, Ch. (2013). Empowerment, organizational commitment and voice behavior in the hospitality industry: Evidence from a multi-national sample. Cornell Hospitality Quarterly, 54, 136 - 148.

Raub, S.P., \& Liao, H. (2012). Doing the right thing without being told: Joint effects of initiative climate and general self-efficacy on employee proactive customer service performance. Journal of Applied Psychology, 97, 651-667.

Rousseau, D. M., Sitkin, S. B., Burt, R. S., \& Camerer, C. (1998). Not so different after all: A cross-discipline view of trust. Academy of Management Review, 23, 393- 404.

Salancik, G. R., Pfeffer, H. (1978). A social information processing approach to job attitudes and task design. Administrative Science Quarterly, 23, 224-253.

Schneider, B. (1990). The climate for service: An application of the climate construct. In B. Schneider (Ed.), Organizational climate and culture: 383-412. San Francisco: JosseyBass.

Schwartz, S. H. (1992). Universals in the content and structure of values: Theoretical 
advances and empirical tests in 20 countries. In M. P. Zanna (Ed.), Advances in Experimental Social Psychology (pp. 1-65). San Diego: SAGE.

Stamper, C. L., \& Masterson, S. S. (2002). Insider or outsider? How employee perceptions of insider status affect their work behavior. Journal of Organizational Behavior, 23(8), 875-894.

Stamper, C. L., \& Van Dyne, L. (2001). Work status and organizational citizenship behavior: A field study of restaurant employees. Journal of Organizational Behavior, 22, $517-$ 536.

Van Dyne, L., \& Ang, S. (1998). Organizational citizenship behavior of contingent workers in Singapore. Academy of Management Journal, 41, 692-703.

Van Dyne, L., \& LePine, J. A. (1998). Helping and voice extra role behaviors: Evidence of construct and predictive validity. Academy of Management Journal, 41, 108-119.

Van Dyne, L., Cummings, L. L., \& MacLean Parks, J. 1995. Extra-role behaviors: In pursuit of construct and definitional clarity. In L. L. Cummings \& B. M. Staw (Eds.), Research in Organizational Behavior (pp. 215-285). Greenwich: JAI Press.

Wang, J., \& Kim, T. (2013). Proactive socialization behavior in China: The mediating role of perceived insider status and the moderating role of supervisors' traditionality. Journal of Organizational Behavior, 34(3), 389-406.

Williams, L. J. \& Anderson, S. E. (1991). Job satisfaction and organizational commitment as predictors of organizational citizenship and in-role behaviors. Journal of Management, 17, 601-617. 
Table 1- Zero-order correlations and reliabilities for individual-level variables

\begin{tabular}{|c|c|c|c|c|c|c|c|c|c|c|c|c|c|c|}
\hline Variable & Mean & SD & 1 & 2 & 3 & 4 & 5 & 6 & 7 & 8 & 9 & 10 & 11 & 12 \\
\hline 1. Gender & .36 & .48 & & & & & & & & & & & & \\
\hline 2. Age & 28.00 & 4.86 & $-.23 * *$ & & & & & & & & & & & \\
\hline 3. Tenure & 1.01 & .91 & -.08 & $.21^{* *}$ & & & & & & & & & & \\
\hline 4. Work Status & .60 & .49 & .04 & $.16^{*}$ & $.45^{* *}$ & & & & & & & & & \\
\hline 5. Seasonal Employment & .75 & .43 & -.04 & $.16^{*}$ & $.53^{* *}$ & .04 & & & & & & & & \\
\hline 6. PIS & 4.01 & .60 & .01 & $.15^{*}$ & $.41^{* *}$ & $.29 * *$ & $.46^{* *}$ & .84 & & & & & & \\
\hline 7. Core job characteristics & 3.30 & .76 & -.11 & $.21^{* *}$ & $.39 * *$ & $.15^{*}$ & $.41^{* *}$ & $.62 * *$ & .96 & & & & & \\
\hline 8. Job Satisfaction & 3.68 & .83 & .00 & $.20 * *$ & $.44^{* *}$ & $.17^{*}$ & $.49 * *$ & $.61^{* *}$ & $.69 * *$ & .84 & & & & \\
\hline 9. Turnover Intention & 2.29 & .96 & .04 & $-.18^{* *}$ & $-.34 * *$ & -.14 & $-.55^{* *}$ & $-.53 * *$ & $-.61^{* *}$ & $-.57 * *$ & .90 & & & \\
\hline 10. In-Role Performance & 3.55 & .84 & .02 & .13 & $.47^{* *}$ & $.23^{* *}$ & $.46^{* *}$ & $.54^{* *}$ & $.65^{* *}$ & $.66^{* *}$ & $-.63 * *$ & .94 & & \\
\hline 11. Voice Behavior & 3.14 & .88 & -.14 & .13 & $.33^{* *}$ & .12 & $.26^{* *}$ & $.44^{* *}$ & $.61^{* *}$ & $.54^{* *}$ & $-.48 * *$ & $.62 * *$ & .93 & \\
\hline 12. Personal Initiative & 3.05 & .91 & $-.22 * *$ & .11 & $.29 * *$ & .03 & $.24^{* *}$ & $.45^{* *}$ & $.63^{* *}$ & $.57 * *$ & $-.44 * *$ & $.61^{* *}$ & $.84^{* *}$ & .89 \\
\hline
\end{tabular}

For gender: $0=$ male, $1=$ female; age and tenure measured in years.

For work status: 0 = part-time, 1 = full-time; for seasonal employment: 0 = seasonal employment, 1 = permanent employment.

Bold figures on the main diagonal are scale reliabilities (Cronbach's alpha).

$* \mathrm{p}<.05 ; * * \mathrm{p}<.01$ 
Table 2- Results of CFAs.

\begin{tabular}{|l|c|r|r|r|r|r|r|l|}
\hline \multicolumn{1}{|c|}{ Model } & \multicolumn{1}{c|}{ df } & \multicolumn{1}{c|}{$\mathbf{X}^{\mathbf{2}}$} & RMSEA & NFI & CFI & IFI & SRMR & \multicolumn{1}{|c|}{$\Delta \mathbf{X}^{\mathbf{2}}$} \\
\hline $\begin{array}{l}\text { Model 1: } \\
\text { f factor }\end{array}$ & 1539 & 9009.81 & .16 & .91 & .93 & .93 & .093 & \\
\hline $\begin{array}{l}\text { Model 2: } \\
2 \text { factor }\end{array}$ & 1538 & 6675.16 & .13 & .92 & .94 & .94 & .086 & $\begin{array}{l}\text { Model 2 vs. Model 1 } \\
\Delta \mathrm{X}^{2}(1)=2334.65 ; \\
\mathrm{p}<.001\end{array}$ \\
\hline $\begin{array}{l}\text { Model 3: } \\
7 \text { factor }\end{array}$ & 1518 & 3950.28 & .089 & .94 & .97 & .97 & .069 & $\begin{array}{l}\text { Model 3 vs. Model 1 } \\
\Delta \mathrm{X}^{2}(21)=5059.53 ; \\
\mathrm{p}<.001\end{array}$ \\
\hline
\end{tabular}


Table 3 - Results of regression model predicting perceived insider status.

\begin{tabular}{|l|c|}
\hline & $\begin{array}{c}\text { DV: Perceived Insider } \\
\text { Status (PIS) }\end{array}$ \\
\hline Age & .04 \\
\hline Gender & .03 \\
\hline Tenure & .08 \\
\hline Work Status & $.23^{* *}$ \\
\hline Employment & $.41^{* *}$ \\
\hline
\end{tabular}

Table entries are standardized regression coefficients (betas). * $\mathrm{p}<.05 ; * * \mathrm{p}<.01$

For gender: 0 = male, $1=$ female. Age and tenure measured in years.

For work status: 0 = part-time, 1 = full-time. For seasonal employment: 0 = seasonal employment, $1=$ permanent employment. 
Table 4 - ANOVA for PIS.

\begin{tabular}{|l|r|r|r|c|}
\hline & Sum of Squares & \multicolumn{1}{c|}{ df } & Mean Square & \multicolumn{1}{c|}{ F } \\
\hline Between Groups & 20.87 & 3 & 6.96 & $27.00 * * *$ \\
\hline Within Groups & 51.26 & 199 & .26 & \\
\hline Total & 72.13 & 202 & & \\
\hline
\end{tabular}

*** $\mathrm{p}<.001$. 
Table 5 - Group means for PIS and multiple comparison results.

\begin{tabular}{|l|r|r|r|}
\hline Groups & N & Mean PIS & $\begin{array}{c}\text { Multiple comparisons } \\
\text { (Scheffe’s F) }\end{array}$ \\
\hline $\begin{array}{l}\text { Group 4 } \\
\text { Permanent, full-time }\end{array}$ & 93 & 4.29 & $\begin{array}{l}\text { Group 4 > Group 3, ** } \\
\text { Group 4 > Group 2, ** } \\
\text { Group 4 > Group 1, ** }\end{array}$ \\
\hline $\begin{array}{l}\text { Group 3 } \\
\text { Permanent, part-time }\end{array}$ & 60 & 3.97 & $\begin{array}{l}\text { Group 3 > Group 2, † } \\
\text { Group 3 > Group 1, ** }\end{array}$ \\
\hline $\begin{array}{l}\text { Group 2 } \\
\text { Seasonal, full-time }\end{array}$ & 28 & 3.67 & Group 2 > Group 1, n.s. \\
\hline $\begin{array}{l}\text { Group 1 } \\
\text { Seasonal, part-time }\end{array}$ & 22 & 3.33 & \\
\hline
\end{tabular}

$\dagger \mathrm{p}<.10 ; * * \mathrm{p}<.01$. 
Table 6 - Results of RCM models for main and interactive effects of core job characteristics and perceived insider status on job satisfaction and turnover intention

\begin{tabular}{|c|c|c|c|c|}
\hline & \multicolumn{2}{|c|}{$\begin{array}{c}\text { DV: } \\
\text { Job Satisfaction }\end{array}$} & \multicolumn{2}{|c|}{$\begin{array}{c}\text { DV: } \\
\text { Turnover Intention }\end{array}$} \\
\hline & Main effects & Interaction & Main effects & Interaction \\
\hline Gender & .06 & .05 & -.02 & .00 \\
\hline Age & .05 & .04 & .03 & .05 \\
\hline Core job characteristics & $.52 * *$ & $.52 * *$ & $-.54 * *$ & $-.55 * *$ \\
\hline Perceived insider status (PIS) & $.22 * *$ & $.21 * *$ & $-.26 * *$ & $-.22 * *$ \\
\hline $\begin{array}{l}\text { Core job characteristics x } \\
\text { Perceived insider status (PIS) }\end{array}$ & & -.06 n.s. & & $.15 * *$ \\
\hline
\end{tabular}

For gender: 0 = male, $1=$ female. Age measured in years.

Table entries are standardized regression coefficients (betas). * $\mathrm{p}<.05 ; * * \mathrm{p}<.01$ 
Table 7 - Results of RCM models for main and interactive effects of core job characteristics and perceived insider status on in-role performance, voice behavior and personal initiative

\begin{tabular}{|l|c|c|c|c|c|c|}
\hline & \multicolumn{2}{|c|}{$\begin{array}{c}\text { DV: } \\
\text { In-role Performance }\end{array}$} & \multicolumn{2}{c|}{$\begin{array}{c}\text { DV: } \\
\text { Voice Behavior }\end{array}$} & \multicolumn{2}{c|}{$\begin{array}{c}\text { DV: } \\
\text { Personal Initiative }\end{array}$} \\
\hline & Main effects & Interaction & Main effects & Interaction & Main effects & Interaction \\
\hline Gender & .07 & .05 & -.05 & -.04 & $-.14^{* *}$ & $-.13^{* *}$ \\
\hline Age & -.04 & -.06 & -.05 & -.04 & -.05 & -.04 \\
\hline Core job characteristics & $.47 * *$ & $.48 * *$ & $.44 * *$ & $.44 * *$ & $.48 * *$ & .47 \\
\hline Perceived insider status (PIS) & $.18^{* *}$ & $.15^{* *}$ & $.15^{* *}$ & $.18^{* *}$ & $.14^{*}$ & $.17^{* *}$ \\
\hline $\begin{array}{l}\text { Core job characteristics X } \\
\text { Perceived insider status (PIS) }\end{array}$ & & $-.13^{* *}$ & & $.11^{*}$ & & $.10^{*}$ \\
\hline
\end{tabular}

For gender: 0 = male, 1 = female. Age measured in years.

Table entries are standardized regression coefficients (betas). ${ }^{*} \mathrm{p}<.05 ;{ }^{* *} \mathrm{p}<.01$. 
Figure 1 - Hypothesized model

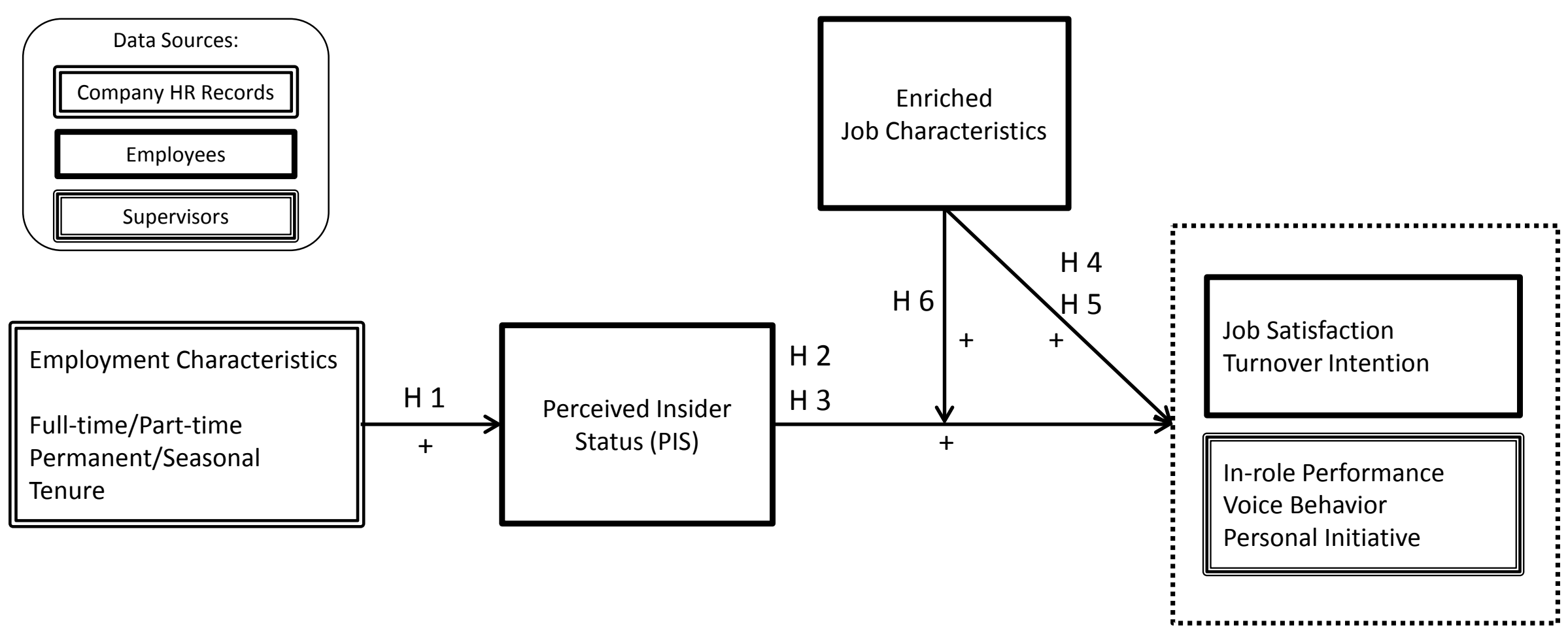


Figure2 - Interaction plot for turnover intention

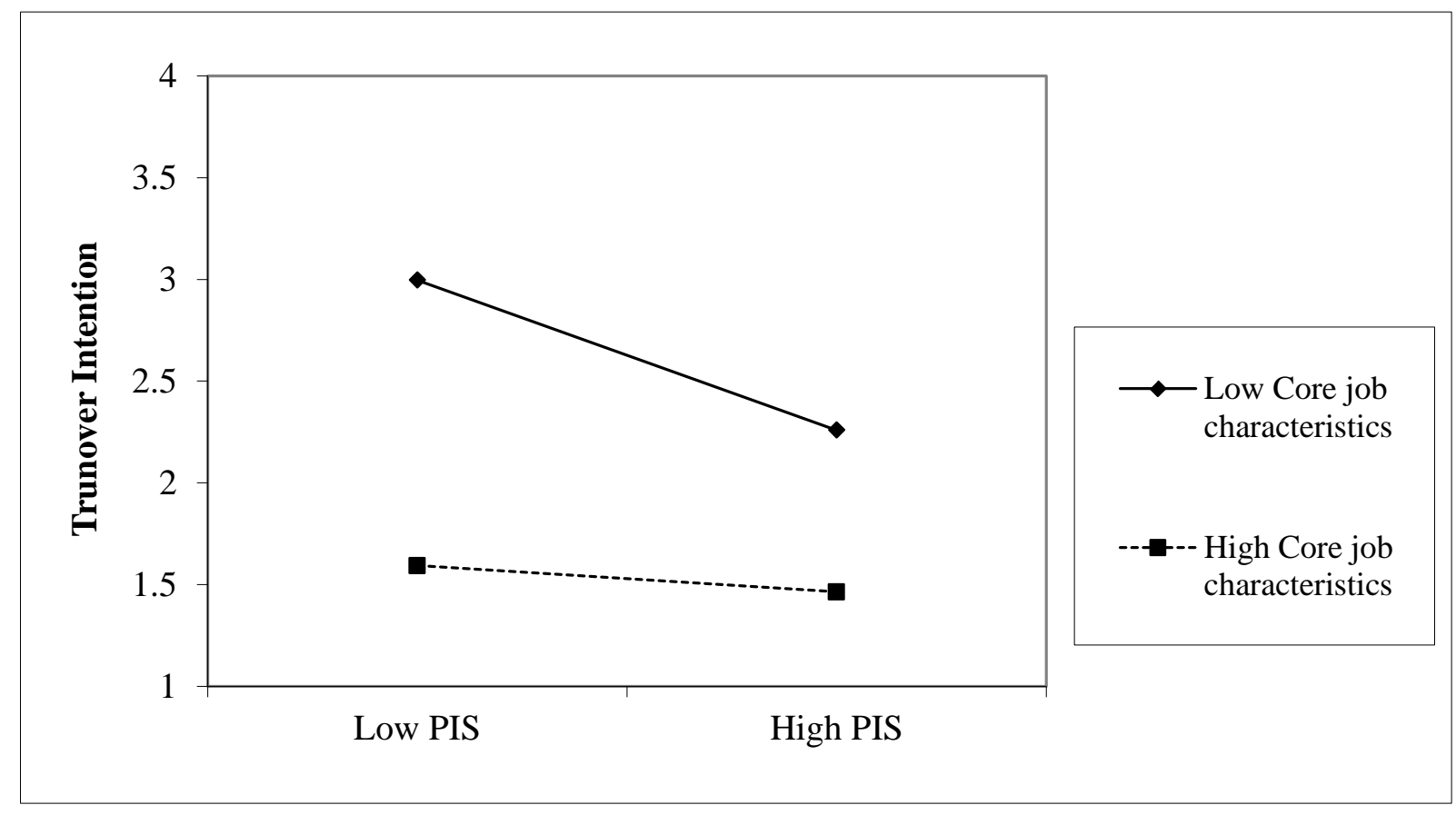


Figure 3 - Interaction plot for in-role performance

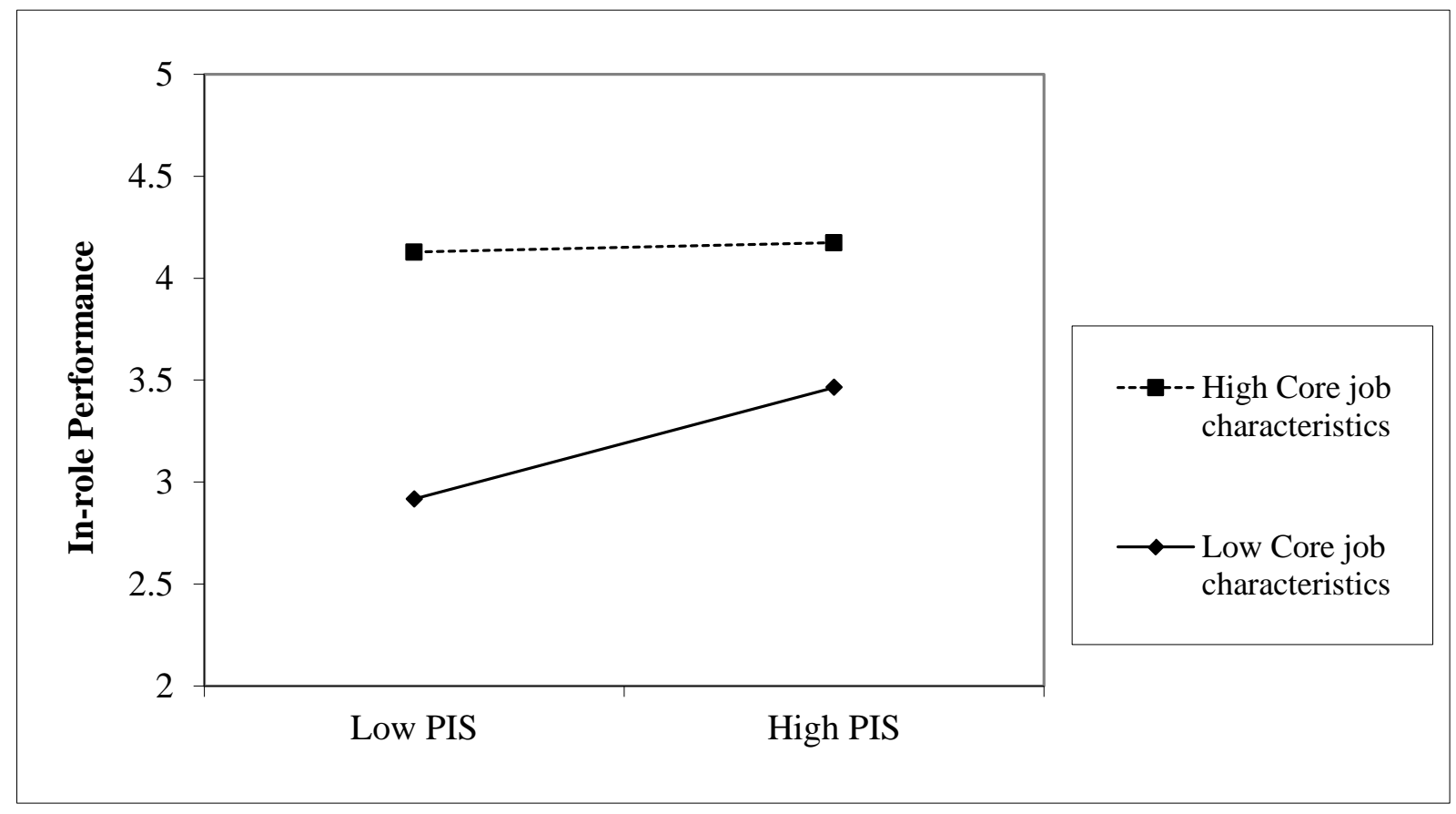


Figure 4 - Interaction plot for voice behavior

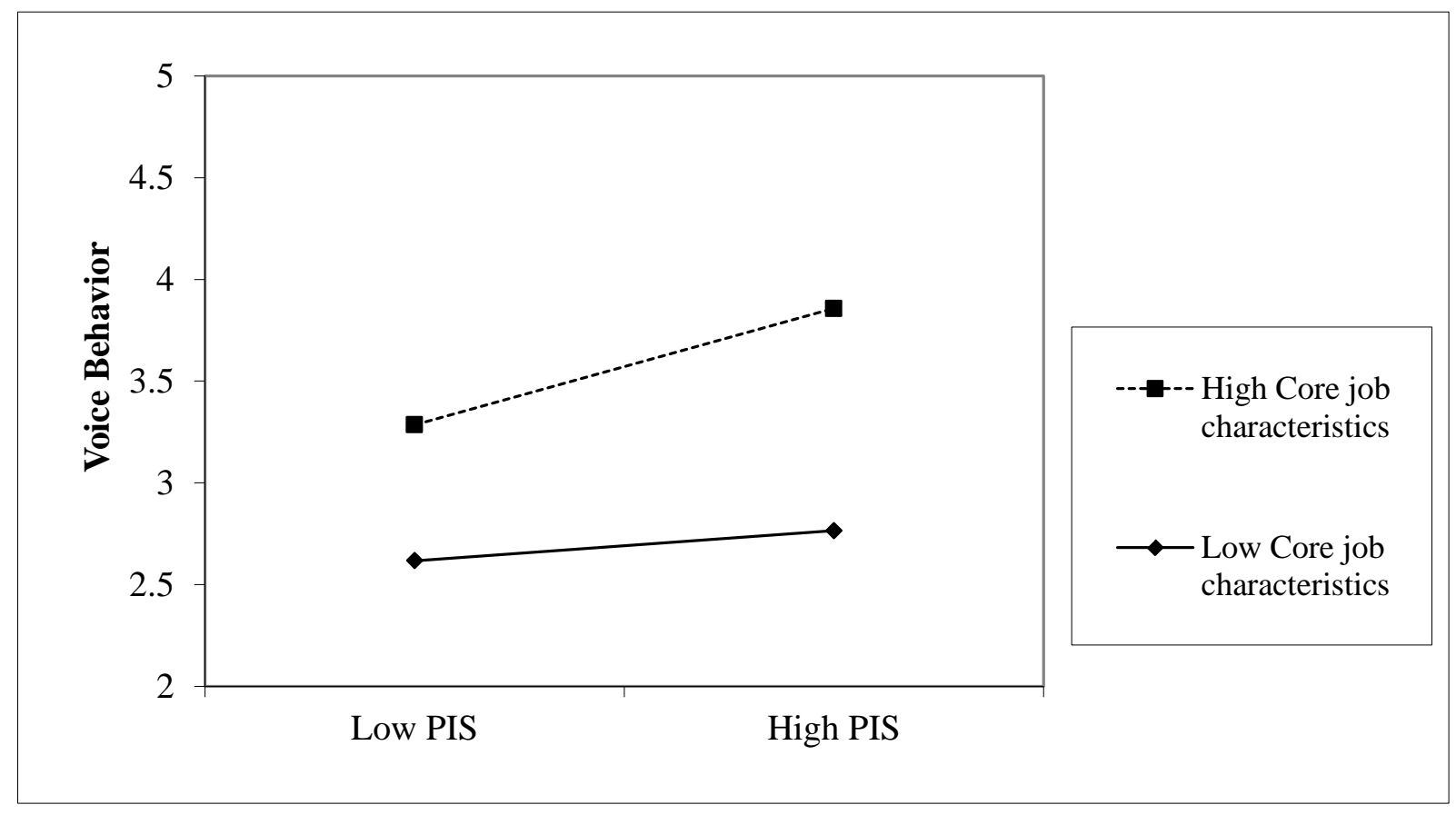


Figure 5 - Interaction plot for personal initiative

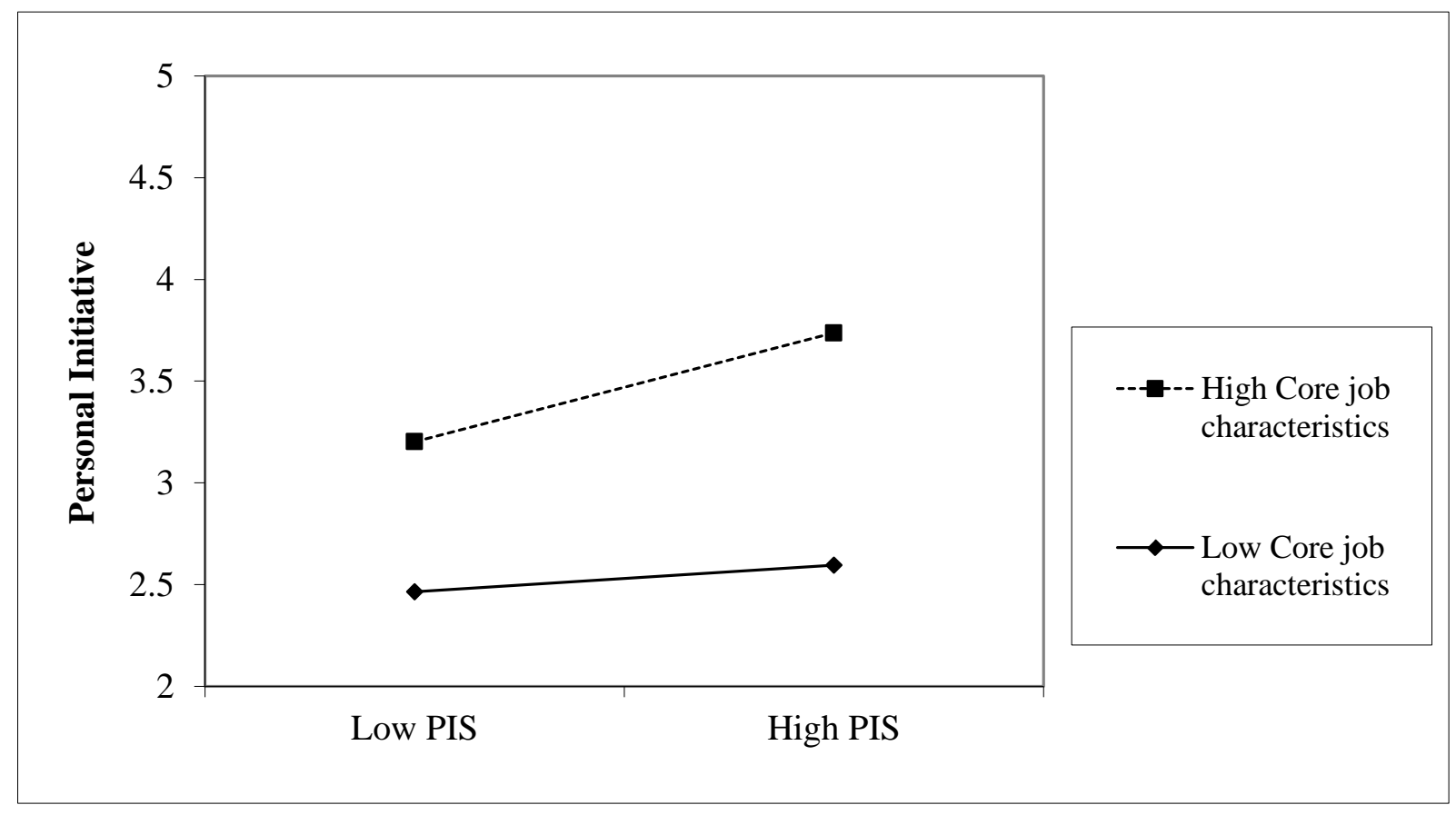

